\title{
NERVOUS ORGANS IN THE PERICARDIAL CAVITY OF THE DECAPOD CRUSTACEA
}

\author{
By J. S. Alexandrowicz \\ The Plymouth Laboratory
}

\section{(Plates I-IV and Text-figs. I-4)}

The observations on nervous organs in the Stomatopoda which led to the assumption that they might have a neurosecretory function (Alexandrowicz, I952 $a$, and in press) gave an impulse to the search for similar organs in other crustaceans, the more so because during the course of the work on the innervation of the heart of these animals a peculiar arrangement of nervous elements in the pericardium had been noticed (Alexandrowicz, I929, I932). An examination of these previously casually observed elements has shown that they are parts of a system of fibres which are the subject of the present account, and for which the term 'pericardial organs' is proposed.

The observations were made on different species of decapod crustaceans with preparations stained in methylene blue. The pericardial organs stain readily in a solution of this dye (IO-I5 drops of $0.5 \%$ solution of methylene blue in distilled water to Ioo c.c. of sea water) provided they are exposed in the proper way. Some hints how this should be done are given below, as they can be better understood when the arrangement of these elements, which is not the same in various species, is known. The fixation and further treatment were the same as described previously (Alexandrowicz, I95I).

\section{GenERAL Remarks and Nomenclature}

A characteristic feature of the nerves in the pericardium is that their branches break up into fine fibrils forming neuropile-like networks. These can be distributed either in the connective tissue ensheathing bundles of thicker nerve-fibres or in plexuses spreading over membraneous parts of the pericardium. The first arrangement produces what will be called 'trunks' and the second 'plexuses' of the pericardial organs. It must be pointed out that they are not totally separated from other nerves. In fact, as we shall see, through the trunks may pass motor fibres and processes of muscle receptor cells. In some instances the pericardial organs are represented by neuropiles accompanying a nerve bundle for a short distance only, but there hardly can be any mistake about their belonging to the same system.

It should be added that the pericardium itself receives another set of fibres 
not entering into this system, viz. the fibres supplying the muscles of the pericardium. Some data about these nerves were given previously (Alexandrowicz, 1932) and will not be discussed in the present paper.

The term 'neuropile' is adopted in order to indicate a very dense and intricate arrangement of the nerve endings. It may be objected that it evokes a picture of a rather three-dimensional structure, as in the central nervous system, while in the pericardium these terminations are spread in a thin stratum (even in the trunks they are on their periphery) and, moreover, the fibrils may appear as strands running in the same direction. However, no other short designation proves to fit them better and, besides, the neuropiles in the central nervous system may have various arrangements (see Hanström, I928, p. 44).

\section{OBSERVATIONS}

\section{Brachyura}

Among the Brachyura the following species were investigated: Maia squinado, Cancer pagurus, Portunus puber, $P$. depurator and Carcinus maenas. The smaller species proved to be less suitable for this purpose and after it had been found that there are only minor differences in the arrangement of the organs in all the crabs investigated the work was carried on with Maia and Cancer which were obtainable in every size required.

The pericardial organs in crabs are composed of thick nervous trunks anastomosing with each other according to a characteristic pattern. They lie on the inside of the lateral pericardium wall in such a position that their stoutest parts span the three openings of the branchio-cardiac veins. For facilitating the description these thickest parts will be called anterior and posterior bars, and those uniting the two bars will be called longitudinal trunks.

In Maia, the anterior bar has a comparatively simple shape, as seen in Text-fig. I and Pl. I, fig. I, and the various specimens examined have shown no great deviation from this pattern. It crosses obliquely the first two openings of the veins and sends through the first of them a stout prolongation which runs far into the vein up to the point indicated by a cross in Text-fig. I. There are two other prolongations, of smaller calibre: one running into the same vein but situated more dorsally and not extending so far, the other directed ventrally.

The posterior bar stretches opposite the 3 rd opening which serves for the supply of blood from two veins which join just before they reach the pericardium. This bar has the form of a crescent and may have a more variable appearance owing to the anastomoses of its parts (Text-fig. I ; Pl. I, figs. I, 2).

The longitudinal trunks, three in number, run more or less parallel to each other linking the two bars. Sometimes, but rather exceptionally, an additional trunk may be seen, or an anastomosing branch passes from one trunk to 
another. All these elements of the pericardial organs, at certain points only, are attached to the pericardial wall. These are: (i) points where the nerves connected with the trunks enter or leave the pericardial cavity; (ii) attachments of the strands which secure the position of the bars and the trunks; (iii) a part of the middle longitudinal trunk which is applied to the pericardium wall. With the exception of the latter all other parts are floating free in the pericardial cavity. The anterior prolongations are also floating in the lumen of the vein, being attached only at the points indicated.

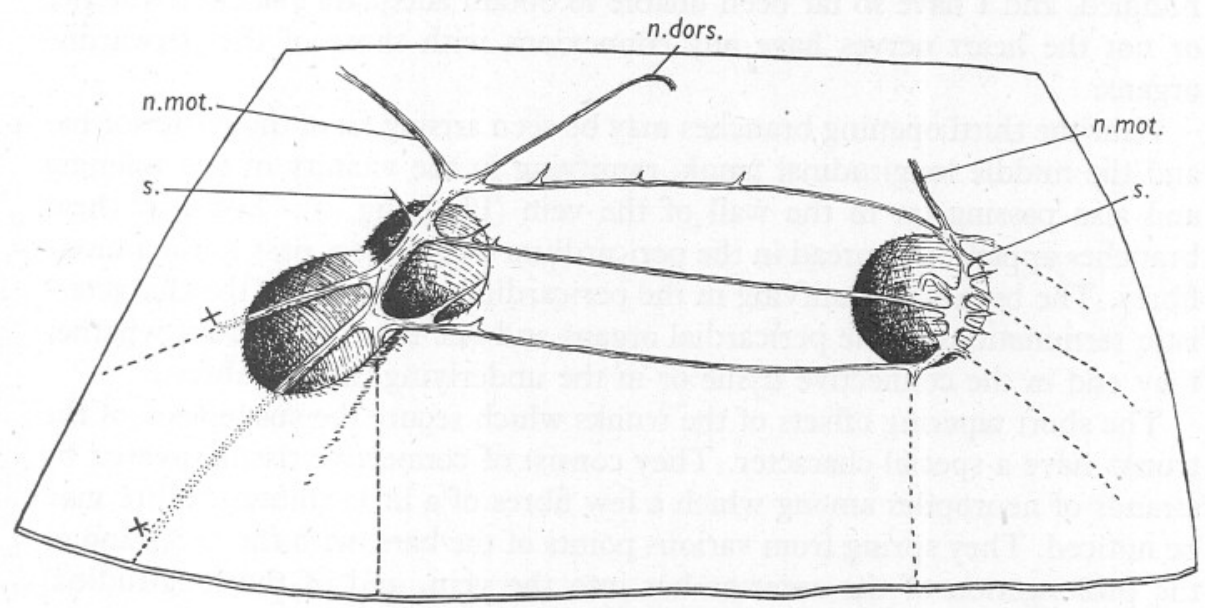

Text-fig. I. Maia squinado. Semi-diagrammatic view of the pericardial organs of the right side, with part of the lateral pericardium wall showing the three openings of the branchiocardiac veins. The nerves running from the central nervous systems into the pericardial organs are drawn in dotted lines. The points at which the two anterior nerves pass into prolongations of the bar situated in the lumen of the vein are indicated by crosses. n.mot., nerves running to the muscles; n.dors., dorsal nerve of the heart; s., strands suspending the trunks.

Connected with the trunks are: (i) nerves coming from the central nervous system; (ii) nerves arising from the trunks but not belonging to the system of the pericardial organs; (iii) strands securing the trunks.

The nerves from the central ganglia pass into the bars. The anterior one is joined by three nerves. The first and the second run into two prolongations situated in the anterior vein, the third runs along the vein of the second opening. How many nerves join the posterior bar is more difficult to determine. One can see five or even six of them approaching the bar from the ventral side and from behind. One stout nerve runs in the wall of the vein. It may be that some are composed exclusively of fibres which only pass through the bar to the muscles, others may be branches of the same segmental nerve. It may be assumed that no less than four segmental nerves reach the posterior bar, but this estimation is not certain. 
The nerves coming from the central nervous system and entering the bars carry also fibres which have a different destination. These are: (i) fibres innervating the muscles situated at the dorsal edge of the thoracic epimera (n.mot., Text-fig. I, Pl. II, fig. 6); (ii) fibres running to the heart as a nerve called n. cardiacus dorsalis (Alexandrowicz, I929, I932) (n.dors.). The former are sometimes distinctly seen simply to pass through the bars without entering into relation with their fibres (mot., P1. II, fig. 5). The heart nerves, however, pass through that portion of the anterior bar in which the fibres are intermingled, and I have so far been unable to obtain adequate evidence whether or not the heart nerves have any connexions with those of the pericardial organs.

Near the third opening branches may be seen arising from the posterior bar and the middle longitudinal trunk, ramifying in the vicinity of this opening and also passing on to the wall of the vein (Pl. I, fig. 2). Some of these branches apparently spread in the pericardium wall, others pass to the muscle fibres. The branches ramifying in the pericardium do not show the characteristic terminations of the pericardial organs and one may be in doubt whether they end in the connective tissue or in the underlying muscle fibres.

The short tapering offsets of the trunks which secure the suspension of the trunks have a special character. They consist of connective tissue covered by strands of neuropiles among which a few fibres of a little stouter calibre may be noticed. They spring from various points of the bars, with the exception of the prolongation of the anterior bar into the vein, and of the longitudinal trunks, with the exception of that part of the middle one which is applied to the pericardium wall.

It may be mentioned that at the dorsal end of the anterior bar there is a nerve cell with long processes, one of which, the axon, passes through this bar towards the central ganglia (n.c., Pl. II, fig. 6). This cell belongs perhaps to a special category of muscle receptor cells found in the Macrura and which will be mentioned later. In Maia I have noticed only one cell in this region and I was unable to ascertain where its processes end.

In other crabs the arrangement of the pericardial trunks shows some differences. In Cancer pagurus, instead of a single anterior bar, there are four or five short ones joined in the manner shown in Text-fig. 2A. Two thick prolongations pass through the first opening into the branchio-cardiac vein. The posterior bar is more or less similar to that of Maia. The longitudinal trunks are more irregularly arranged than in Maia, for, starting from the anterior bars, they may divide and send branches into another trunk, or two of them may unite into one (Text-fig. $2 \mathrm{~A}$; cf. Pl. I, fig. 4). Only the anterior and posterior portions of the longitudinal trunks are floating free, since for about half or more of their total length they are embedded in the tissue of the pericardum wall where they are deprived of the neuropile sheath.

In Portunus puber and P. depurator the arrangement of the anterior bars is 


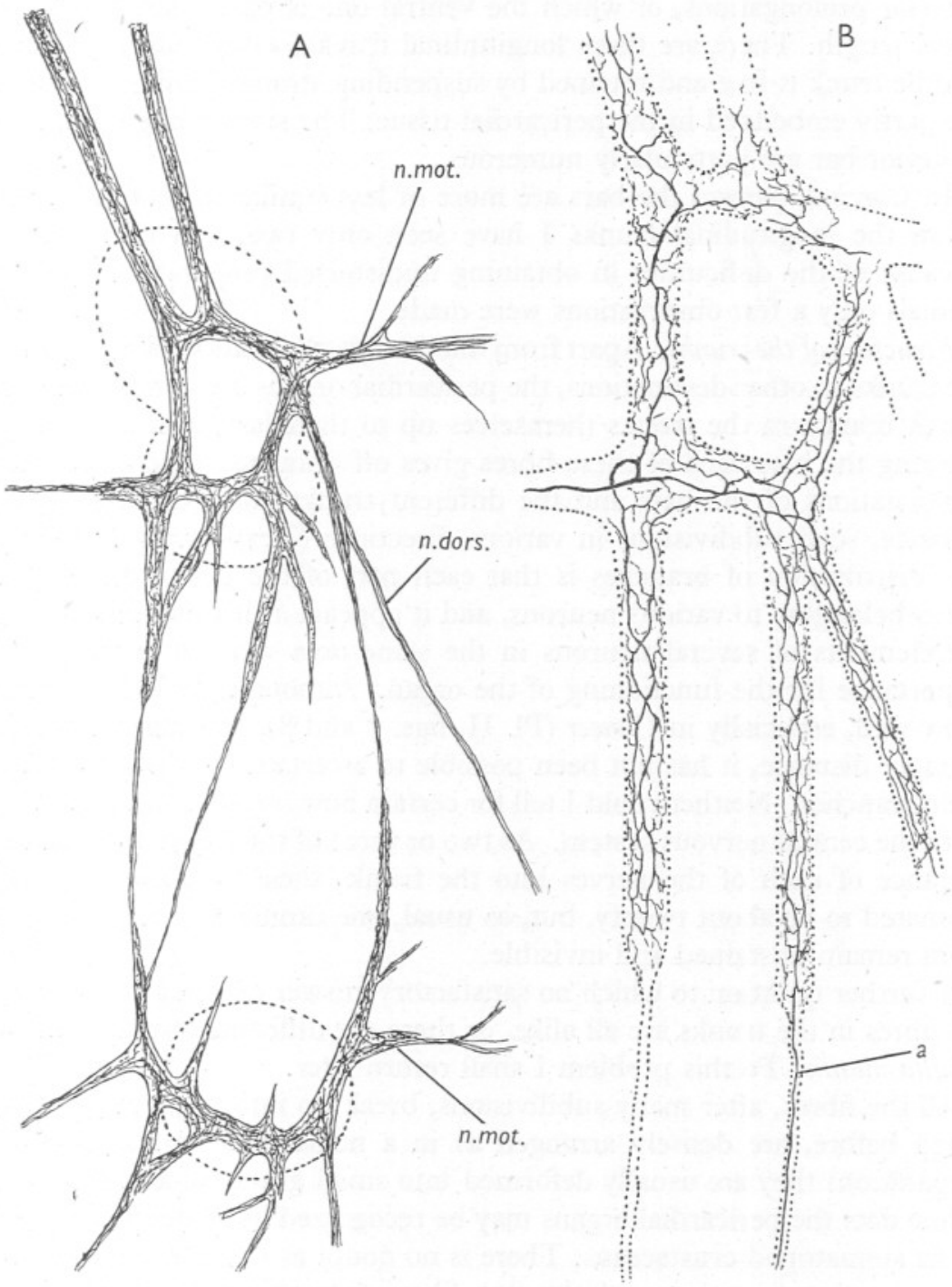

Text-fig. 2. Cancer pagurus. A, pericardial organ of the right side. The outlines of the openings of the veins are indicated by a dotted line. Note the different appearance of the longitudinal trunks losing their neuropile sheaths in the middle of their course (cf. Pl. I, fig. 4); n.mot., motor nerves; n.dors., dorsal nerve of the heart. B, ramification of one fibre entering the anterior bar; $a$, fibre running towards the posterior bar. Finer ramifications are not represented. 
about the same as in Cancer, only the bars appear somewhat longer. The two anterior prolongations, of which the ventral one is particularly thick, are of equal length. There are three longitudinal trunks, as in Maia, but here the middle trunk is free and retained by suspending strands while the two others are partly embedded in the pericardial tissue. The suspending strands of the posterior bar are particularly numerous.

In Carcinus maenas the bars are more or less similar to those in Portunus. From the longitudinal trunks I have seen only two, and both were free. Because of the difficulties in obtaining undistorted preparations from these animals only a few observations were made.

Structure of the trunks. Apart from those nerve elements which pass through the trunks to other destinations, the pericardial organs are composed of fibres which branch in the trunks themselves up to their last terminations. After entering the bars each of these fibres gives off branches which pass into the prolongations of the bars and the different trunks and, running for a long distance, send subdivisions in various directions (Text-fig. 2B). A result of this distribution of branches is that each part of the pericardial organ has fibres belonging to various neurons, and it appears as if this intermingling of the elements of several neurons in the same area were of some particular importance for the functioning of the organ. Although the individual fibres show well, especially in Cancer (P1. II, figs. 7 and 8), and may be traced for a longer distance, it has not been possible to ascertain the distribution of all their branches. Neither could I tell for certain how many of these fibres come from the central nervous system. As two or three of them may be found at the entrance of each of the nerves into the trunks their total number may be estimated to be about twenty, but, as usual, one cannot be sure that some of them remain unstained and invisible.

A further question to which no satisfactory answer can be given is whether the fibres in the trunks are all alike, or there are different sorts of them as in Squilla mantis. To this problem I shall return later.

All the fibres, after many subdivisions, break up into fine fibrils which, as stated before, are densely arranged as in a neuropile. In methylene-blue preparations they are usually deformed into small granules, and by this mass of fine dots the pericardial organs may be recognized in all decapod as well as in the stomatopod crustaceans. There is no doubt as to their nervous nature, since the transformations of the fine fibres into small beads can be often observed, but nothing can be said about the histological structure of such ostensibly deformed elements.

In the trunks which are cylindrical in shape the various fibres are so arranged that the thicker are nearer to the axis with their branches approaching the periphery at which the neuropiles form a superficial layer. This arrangement can be best observed in Cancer. All the fibres are held together by connective tissue which does not stain with methylene blue. In sections it 
may be seen that this tissue fills the spaces between the nerve fibres, forming concentric layers around the thicker of them. The nerve fibres are not so tightly packed as in the lamellae of Squilla. Apart from scattered nuclei, seemingly belonging to the connective tissue and the neurolemma, there may be seen cells with granular cytoplasm showing the characteristic features of amoebocytes and which are evidently brought into the trunks by small arteries. Except for these cells no elements in the trunks could be noticed having special affinity to eosin, acid fuchsin, or dyes entering in the Azanmixture.

The pericardial organs in crabs are easily accessible. After removing the carapace, the dorsal pericardium wall, and cutting through the dorsal ligaments of the heart, one can see the pericardial organs spanning the openings of the veins or applied to the wall near to these openings, the latter position evidently due to the adherence of blood clots to the organs and the neighbouring parts. As these organs are attached at few points it is possible to cut them out, but for staining it is better to cut out the epimeral plates leaving the organs in situ. The preparation, after trimming the protruding parts, should be fixed to the paraffin plate and put into methylene-blue solution. The removal of the chitin and the muscles should be made later, during washing after fixation. The chitin then detaches quite easily. Final cleaning up, as removing the last of the muscle tissue and cutting out parts of pericardium membrane obstructing the view, can be made when the preparations have been taken to xylol.

The pericardial organs can also be approached from the ventral side. It is then advisable, when removing the carapace, to leave in place the membrane covering the pericardial cavity from the dorsal side and cut out the epimeral plates with the heart attached to them. After stretching the preparation with its inside uppermost the ventral pericardium wall (pericardial septum) should be cut through on each side of the heart, preferably with the adjoining half of the ventral heart wall, and stretched so that the pericardial cavity is well exposed from the inside. This method has its advantages for the observation of the nerves passing through the pericardial trunks to the muscles and to the heart. The latter nerve, however, is elusive and there are some difficulties in tracing it up to the heart.

\section{Eupagurus bernhardus}

In Eupagurus the most conspicuous parts of the pericardial organs appear as two trunks curving along the sides of the heart as shown in Text-fig. $3 \mathrm{~A}$ (cf. Pl. III, fig. 9). These trunks vary in thickness and in some places divide into strands which unite again. Trunks of smaller dimensions connected with these main trunks are of two sorts: some conveying fibres from the central nervous system, others being branches given off by the trunks. It is often difficult to distinguish one sort from another, since, at the points where they join the main trunks, fibres from the trunks may pass into the nerves of central origin to run in the same nerves in the opposite direction. They can be identified if it can be stated that farther away they leave this nerve, but more than often after seeing a portion of such mixed nerve one remains in doubt in which direction its fibres may run. Moreover, as the branches of the trunks tend to anastomose in a plexus the tracing of fibres is very uncertain.

It may be assumed that no less than five segmental nerves are sent by the 
central ganglia to form the pericardial organs but possibly there are more of them. It is also uncertain whether they all belong to the thoracic segments since one of them coming from behind can be followed so far backwards that its origin in the Ist abdominal segment is probable.

The branches arising from the trunks are of various lengths. Some at a short distance form a plexus spreading over the lateral pericardium wall which as a thin membrane covers the muscles inserting into the epimeral plate; the longer ones pass on to the farther parts of the pericardium and to the heart ligaments. An anastomosing branch links the posterior ends of the main trunks (Text-fig. 3A).

The fibres arising from the trunks and from their branches have various destinations. Some of them run to supply the muscle fibres which in the pericardium of Eupagurus are more abundant than in other species investigated. Others ending in neuropiles can be regarded as the elements of the pericardial organs. Their arrangement and distribution is much less uniform than in crabs, since they are present not only in the form of the trunks but as strands extending plexus-like over the pericardium wall or accompanying branches of the nerves.

Nor in Eupagurus was it possible to determine the areas of expansion of individual neurons, although the nerves stain well, and this animal would perhaps be the most suitable for this kind of investigation were it not so difficult to obtain preparations in which the trunks could be observed for a sufficient distance. The details which could be noticed confirm the observations made in crabs. Thus it can be seen that one fibre gives off branches passing into different parts of the trunk (Pl. III, fig. IO). It can also be stated that the nerves coming from the central nervous system each carry more than one fibre to the pericardial organs, and that the fibres brought in by different nerves overlap each other in their terminal distribution. The presence of an anastomosis through which the fibres pass into the trunks of the opposite side shows that in the neuropiles the contralateral neurons also take part.

The structure of the trunks resembles greatly that described previously in crabs, the main difference consists in that the trunks in Eupagurus are not cylindrical but more flattened, and that there is less connective tissue between the fibres. Otherwise the branching of the thicker fibres resulting in forming the neuropiles appears to follow the same pattern.

In Eupagurus it is better to expose the pericardial organs approaching them from the ventral side. After the thorax has been opened from this side and the gonads and digestive organs removed, the preparations should be spread so that the pericardial septum is well exposed. It is advisable not to try to open the pericardial cavity before the trunks of the pericardial organs, which stain readily even when covered by this membrane, become visible. Even without taking away this membrane they show fairly well in mounted preparations. In any case good preparations are difficult to obtain, for on removing the chitinous parts the pericardial organs are easily damaged or displaced. 


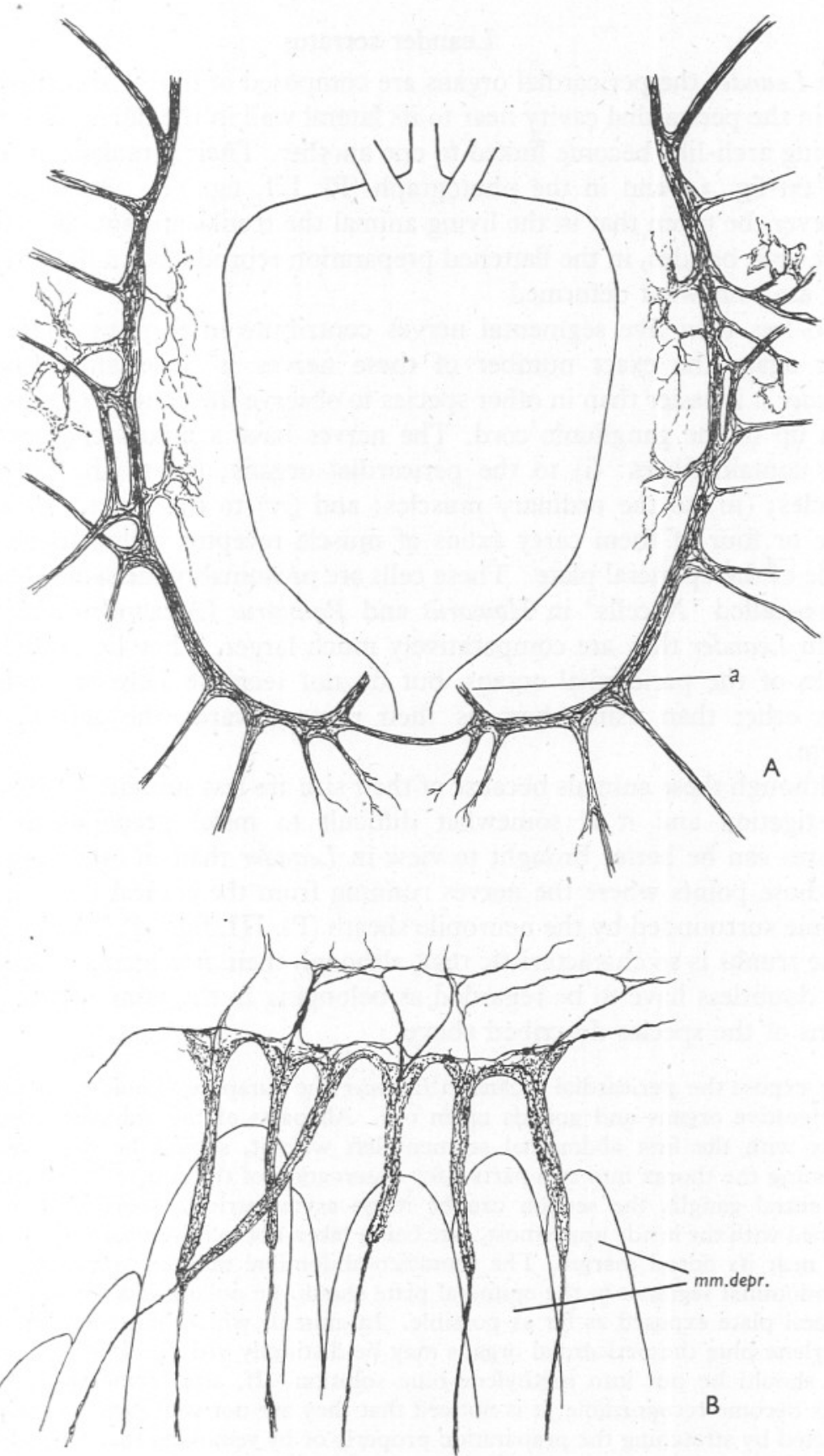

Text-fig. 3. A, Eupagurus bernhardus. Pericardial organs flanking the heart. $a$, branches running in the dorsal direction, shown as cut. B, Leander serratus. Pericardial organs of the right side. mm.depr., musculi depressores. Other muscles in this region are not represented. 


\section{Leander serratus}

In Leander the pericardial organs are composed of five or six trunks which run in the pericardial cavity near to its lateral wall in the dorsal direction and curving arch-like become linked to one another. Their arrangement is shown in Text-fig. 3 B and in the photograph (P1. III, fig. II). Account should, however, be taken that in the living animal the trunks are not all in the same plane and, besides, in the flattened preparation reproduced in the photograph they are somewhat deformed.

No less than five segmental nerves contribute in forming these organs. Here again the exact number of these nerves is uncertain, although in Leander it is easier than in other species to observe the courses of these nerves even up to the ganglionic cord. The nerves have a mixed composition for they contain fibres: (i) to the pericardial organs; (ii) to the pericardium muscles; (iii) to the ordinary muscles; and (iv) to the heart. In addition, three or four of them carry axons of muscle receptor cells situated on the inside of the epimeral plate. These cells are presumably the same elements as the so-called ' $N$-cells' in Homarus and Palinurus (Alexandrowicz, $1952 b$ ), but in Leander they are comparatively much larger. They lie quite near the trunks of the pericardial organs, but do not seem to have any relation to them other than using them as their route towards the central nervous system.

Although these animals because of their size are less suitable for this kind of investigation and it is somewhat difficult to make preparations, certain features can be better brought to view in Leander than in other crustaceans e.g. those points where the nerves running from the central nervous system become surrounded by the neuropile sheath (P1. III, fig. I2). The appearance of the trunks is so characteristic that, although their arrangement is different, they doubtless have to be regarded as belonging to the same category as the organs of the species described above.

To expose the pericardial organs in Leander the carapace should be removed and the digestive organs and gonads taken out. All parts of the animal, excepting the thorax with the first abdominal segment left with it, should be cut away. After sectioning the thorax into two parts-for observation of the course of the nerves into the central ganglia the section can be made asymmetrically-each half has to be attached with the inside uppermost, care being taken not to injure parts of the epimeral plate near its dorsal margin. The thoracico-abdominal muscles stretching from the Ist abdominal segment to the epimeral plate should be pulled aside so as to leave the epimeral plate exposed as far as possible. In animals which had been injected with methylene blue the pericardial organs may be distinctly visible. If not, the preparations should be put into methylene-blue solution. If, after some time, when the trunks become recognizable, it is noticed that they are not well exposed, this may be corrected by stretching the preparation properly or by removing the tissues hindering the staining. 


\section{Homarus vulgaris}

The pericardial organs in Homarus are less conspicuous than in the species previously described, for the fine neuropile-like terminations mostly spread in plexuses forming a very thin layer on the pericardial wall and on heart ligaments, and in but a few places and for a short distance only do they form sheaths surrounding the nerves passing through the pericardial cavity. The nerves around which such sheaths are present, and which in these parts have the appearance of the trunks of pericardial organs, are the Ist to 4 th thoracic nerves (so termed because they come from the Ist to 4th thoracic ganglia, though in fact belonging to the 4 th to 7 th thoracic segments). On the Ist and $4^{\text {th }}$ of these nerves the neuropile sheaths are very short, especially on the former where its presence in many instances seems to be doubtful. On the 2nd and 3rd they are quite distinct (P1. IV, fig. I3). The trunks can be best identified at points where they reach the muscles lying on the inside of the epimeral plate (Text-fig. 4). The Ist and 2 nd at the ventral edge of the m. contractor epimeralis, the 3 rd at the anterior ventral corner of the 2 nd head of the lateral thoracico-abdominal muscle, the 4 th ventrally of the accessory bundles of the same muscle. All trunks stretch between these points and the edge of the dorsal thoracico-abdominal muscles which bulge into the pericardial cavity. The topography of the muscles was described previously (Alexandrowicz, I952 b). The names of those shown in the figure and not mentioned in the paper quoted are those adopted by Schmidt (I9I5).

The 2nd trunk may appear as composed of two or three parts (P1. III; fig. I3); the $3 \mathrm{rd}$, the longest of all, sends strands inserting into the epimeral plate obviously serving the same purpose as similar strands securing the suspension of the trunks in the Brachyura (Pl. III, fig. I4).

Apart from motor fibres which are of stout calibre, there pass through the trunks, as in Leander, the axons of the muscle receptor cells. In the description of these elements in which they were termed $N$-cells (and designated by the numbers $\mathrm{I}-5$ ) the course taken by their axons was not specified. Now I could observe that cell no. 3 sends its axon through the Ist trunk, no. 2 through the 2 nd trunk, and no. I through the 3 rd trunk, into the Ist to 3 rd thoracic ganglion respectively, i.e. they belong to the 4 th to 6th thoracic segments. Through the 4 th trunk pass the axons of the two cells of the muscle receptor organs of the 7 th thoracic segment. No relation has been noticed between the axons of receptor cells and of the motor nerves to the elements of the pericardial organs.

The structure of the trunks is very much the same as in other Decapoda. The differences depend on the comparatively stouter calibre of the motor fibres passing through the trunks; the neuropile sheath in the Ist trunk may look as if it it were formed only at the point where the nerve fibres start expanding on the connective tissue membrane. The quantitative relation of 
the nerve elements may be expressed in such a way that in Brachyura the pericardial organs form trunks through which pass nerve fibres of other sorts, whereas in Homarus and Leander the elements of the pericardial organs are attached to the nerves passing through the pericardial cavity.

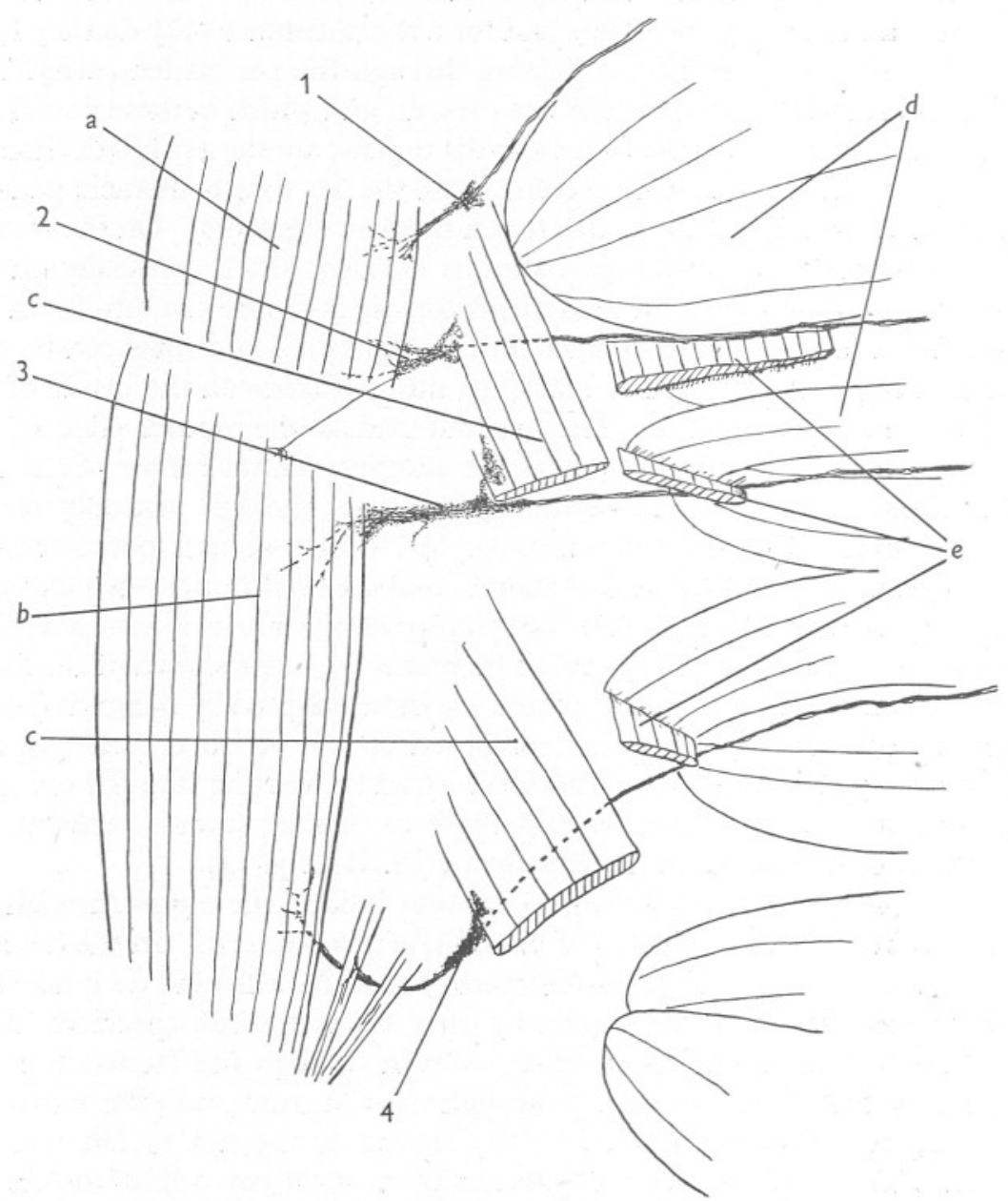

Text-fig. 4. Homarus vulgaris. Topography of the pericardial organs of the left side in relation to the muscles inserting into the epimeral plate. I-4, Ist to 4 th trunks of the pericardial organs. $a, \mathrm{~m}$. contractor epimeralis; $b, \mathrm{~m}$. lateralis thoraco-abdominalis (2nd head); $c, \mathrm{~mm}$. dorsales thoraco-abdominales; $d, \mathrm{~mm}$. depressores; $e, \mathrm{~mm}$. thoracales anteriores.

The small dimensions of the trunks of pericardial organs may perhaps be explained by their topographic relations. There is in Homarus only a narrow space between the epimeral plate and the dorsal thoracico-abdominal muscles 
which pass dorsally from the pericardial septum and lie between this plate and the heart. Since the pericardial organs in the form of trunks need to float free, as seems to be essential for their function, there is no room for the longer trunks, nor presumably can they extend dorso-ventrally as in Leander.

The diminutive dimensions of the trunks in Homarus are compensated by a rich expansion of nerve fibres arising from these trunks and spreading over large areas of the membraneous tissue lining the lateral wall of the pericardium and forming the heart ligaments. The photograph (Pl. IV, fig. I6) shows such fibres starting from the 3 rd trunk, but only the thicker ones are seen fairly well. Actually, strands of the finest filaments spread in plexuses between these fibres and are so densely arranged that at many places little space is left uncovered by fine granules in which the fine fibrils are disintegrating. The nerve elements of this kind appear to be particularly abundant in the vicinity of the trunks. On the dorsal and ventral wall of the pericardium they seem to be missing. This, however, does not imply that the ventral wall is deprived of nerves for, as stated before, there are nerve fibres running here to the muscles of the pericardial septum and to the arterial valves (Alexandrowicz, I932).

Hints about dissection and staining of the nerve elements in this region have been given in the paper quoted dealing with the muscle receptors in the thorax. The technique is much as with Leander, i.e. to approach the nerves from the dorsal side and to turn the epimeral plate in such a way that it becomes exposed from the inside.

It is also possible to observe the trunks in their natural position. After the dorsal wall of the pericardium has been removed the dorsal thoracico-abdominal muscles must be pulled a little aside. Then, through the cleft between these muscles and the epimeral plate, the openings of the branchio-cardiac veins come into view, and stretched above them the 2nd and 3rd trunk of the pericardial organs may be seen. The identification of these trunks may, however, be uncertain, as strands of connective tissue and blood clots may stretch in a similar way. The Ist and the 4 th trunk may be also found, but here the mistakes are more likely to occur. In stained preparations there is no difficulty in distinguishing the nerves from other elements.

\section{Isopoda}

In the pericardial cavity of Ligia oceanica. I noticed two nerve trunks running in a longitudinal direction alongside the heart tube which do not show connexions with other elements innervating the heart and the muscles of the pericardium. It is therefore probable that they might be pericardial organs similar to those in decapods and stomatopods, However, no satisfactory evidence could be obtained, chiefly because of difficulties in exposing the parts of the pericardium for staining. Moreover, these trunks do not stain well, and in the animals of such a small size the character of nerve fibres is difficult to ascertain. 
Palinurus vulgaris, Scyllarus arctus, Astacus fluviatilis

These species have not been examined in the course of the present work, but a mention of observations previously made may be not out of place. In all of them I noticed, when investigating the innervation of the heart, the existence of 'peculiar terminations of the nerves entering the pericardial cavity'. These were doubtless the elements of the pericardial organs, as follows from the statement: 'the thin fibrils which originate from the thicker fibres present a mass of blue points like a "punctate substance" of the neuropiles.... Similar structures can be seen on the epimeral plate and I had previously observed them in Potamobius' (Alexandrowicz, I932, p. 230). In Astacus fluviatilis (then temporarily called Potamobius astacus) I had, moreover, described and pictured a peculiar arrangement of fibres around the dorsal nerves of the heart ending in irregular plates or cell-like bodies (Alexandrowicz, I929). I called it 'apparatus nervi dorsalis', suggesting that it possibly might be concerned with the appreciation of the pressure in the pericardial cavity. In the light of the later findings it seems more probable that it belongs to the system of the pericardial organs, and as a similar body has not been found in other Decapoda it might be of interest to examine it from this angle.*

\section{Discussion}

It has been shown above that the two forms of arrangement of neuropile-like endings, viz. as sheaths round the bundles of fibres or spread in plexuses over a larger area, may predominate in one group of the Crustacea and play a minor role in another. The one extreme is represented in the Brachyura, which possess remarkably large trunks and not any, or at most few, neuropile plexuses. On the other hand, in Homarus the plexuses are widely spread and the trunks are greatly reduced. A question arises: has this different arrangement some bearing on the function of these organs, or is it rather accidental? The morphological evidence is not unequivocal. It may be assumed, as already suggested, that purely topographical conditions are decisive in developing one or the other form. In the crabs, in which there is a wide space in the pericardial cavity, the trunks are free to attain large dimensions; while in Homarus, because of the narrowness of space, the conditions for functioning of the longer trunks are unfavourable and consequently the fibres have to spread out. However, this simple and plausible explanation seems not to tally well with the fact that in the pericardial cavity of Squilla both sorts of neuropiles are present, and apparently there is no such lack of space pre-

* Since sending this paper to the printers I have had the opportunity at Naples of observing the pericardial organs in Eriphia spinifrons, Dromia vulgaris, Pagurus striatus, Lysmata seticaudata and Penaeus camerote. In each of these species the pericardial organs are arranged according to a particular pattern differing to varying degrees from those described above. In Penaeus the plexuses spread over the pericardium wall attain the largest dimensions of all species investigated. 
venting the development of the first sort. (In Squilla these have been designated 'lamellae', but they are nothing else than short flattened trunks.) Thus, since the two forms of neuropiles exist in the same segments and not far from one another, it might be supposed that their functions may not be identical.

Another question which arises on comparing the pericardial organs in decapods with those in stomatopods is the origin of their nerve fibres. In Squilla they have been found to come from two different sources: one set is given off by nerve cells lying in the abdominal segments outside the ganglionic cord, while the second set, of obviously different kind, originates in the foreparts of the central nervous system. Peripheral nerve cells taking part in the forming of the pericardial organs have not been found in decapods, and it is to be assumed that the corresponding elements became centralized. Unless, however, the structure of the pericardial organs has not at the same time become simplified in the Decapoda, the second set of fibres should be present in them. However, the histological examination does not afford evidence to lend sufficient weight to this assumption. There may in places be seen fibres of somewhat different appearance and, in particular, I tried to trace those in the anterior prolongation of the bar (in the Brachyura). But the fibres mix in such a way that no certainty about their special behaviour could be obtained. This, of course, does not imply that similarly looking nerves should be all of the same kind, and that the pericardial organs in the Decapoda carry no fibres of different origin which might have different physiological functions.

In approaching the problem of the function of these organs, it ought to be emphasized that exposure to the blood stream coming from the gills must be a paramount condition for their activity. The trunks are not only in these very places when the blood passes into the pericardium, but they are suspended in such a way that they can be bathed on all sides by the blood. How essential it must be for the neuropiles to be in the closest touch with the blood can be judged by the fact that in the same trunks, as in the longitudinal trunks of crabs, they do not develop at those parts where the trunks are embedded into the tissue of the pericardium, and are abundant where they are free. In other species this position of the trunks is not so easily demonstrable, but whenever it is possible to verify their relation to the pericardium they are found floating in its cavity.

As regards the neuropiles spreading over the membranes in a thin layer, their particular abundance at those places where the blood stream entering the pericardial cavity passes, gives support to the assumption about the vital importance of this kind of topographic relation.

This conclusion affords a clue towards the solution of a problem of the situation of the pericardial organs in the Stomatopoda. In these animals the heart and the pericardial cavity extend over some fifteen segments, but the organs in question are present in five abdominal segments only, and no reason 
for it could previously be found. Now in stomatopods the main respiratory organs, the abdominal gills, which are five in number, are attached to the same five abdominal segments and thus the pericardial organs prove to be situated exactly where the blood from the gills passes to the heart. It is not impossible, also, that an organ of a similar histological structure which in these animals is suspended in the ventral blood sinus, described under the name of 'the transverse bar of the 6th segment' (Alexandrowicz, I952 a), owes its situation to the existence of the so-called thoracic gills. This matter needs further investigation, for the knowledge of the blood circulation in stomatopods is deficient and no precise data seem to have been published about the way taken by the blood passing through the thoracic gills.

In the papers dealing with the innervation of the heart of crustaceans, in which some observations relating to the nerves in the pericardial cavity were made, I expressed the supposition that they might have some sensory function. However, in view of the findings in Squilla mantis this supposition had to be discarded, and it was suggested that these organs release some substances into the blood. The observations made with the Decapoda provide supporting evidence for this hypothesis and, moreover, this could be confirmed by the results of experiments performed in collaboration with $\mathrm{Mr} \mathrm{D}$. B. Carlisle. They have shown that the extracts of pericardial organs, if added to the saline solution perfusing an isolated heart of Cancer or Maia, exhibit a pronounced action on the heart rhythm. It appears probable that one of the substances produced in these organs may be adrenaline or some adrenaline-like compound, as may be inferred from the fact that the extract of the organs of Cancer gives a distinct positive fluorescence test as well as the blood of this animal taken from the pericardial cavity (but not that from the leg arteries). However, the effect of the extract on the heart is not identical with that of adrenaline solution. Consequently, it has to be assumed that the liberated substance is either not adrenaline or the latter is mixed with some other product. Neither of the compounds so far tested, such as noradrenaline, tyramine, acetylcholine and histamine, proved to induce effects identical with those of the pericardial organs extract. The results of these experiments will be published separately.

With regard to the question which elements of the pericardial organs are responsible for their secretory activity the balance of evidence favours the view that these are the terminations of the nerve-fibres. The alternative supposition would be to ascribe this faculty to the connective tissue and consider the nerves as destined only to convey stimuli to this tissue. However, not only does it seem unlikely that connective tissue could exhibit this faculty, but the quantity of nerve elements concentrated in these organs and their predominance over other elements makes such an assumption attributing them a rather secondary role quite untenable. Therefore, all available information considered, there is justification for drawing the conclusion that the 
Crustacea possess in their pericardial cavity organs which by the way of neurosecretion release substances regulating the heart-beat.

I wish to record my gratitude to $\mathrm{Mr}$ G. M. Spooner for his kind help in preparing the manuscript.

\section{SUMMARY}

In the pericardial cavity of the decapod Crustacea the nerve fibres end in characteristic neuropile-like networks which surround bundles of thicker fibres or spread over the pericardium wall and the heart ligaments. It is proposed to designate the whole system of these elements as 'pericardial organs'.

The arrangement of the elements constituting the pericardial organs varies in different groups of the Decapoda. In the Brachyura the bundles of fibres surrounded by neuropiles form conspicuous trunks linked with each other; the main parts of these trunks are situated at the openings of the branchiocardiac veins into the pericardial cavity. In Eupagurus bernhardus two main trunks flank the heart giving off branches which spread in various directions and form at some places plexuses on the pericardium wall. In Leander serratus the pericardial organs are represented by several trunks running near the lateral wall of the pericardium in the dorsal direction and uniting by archshaped branches. In Homarus vulgaris there are four comparatively much shorter trunks situated at the lateral wall of the pericardial cavity, but plexuses of neuropile-like nerve fibres spread over large areas.

The trunks of the pericardial organs are suspended in the pericardial cavity in such a position that they may be bathed on all sides by the blood passing from the gills. The plexuses extending over the membranes are situated in places also exposed to the blood stream. There is evidence indicating that the pericardial organs produce substances influencing the heart-rhythm. It is assumed that these substances are liberated into the blood by a process of neurosecretion occurring at the terminations of the nerves.

\section{REFERENCES}

Alexandrowicz, J. S., I929. Badania nad unerwieniem serca raka (Potamobius astacus). Recherches sur l'innervation du cœur de l'Ecrevisse (Potamobius astacus). Folia Morphologica, Vol. I, pp. 37-68. [Polish with French abstract.]

- 1932. The innervation of the heart of the Crustacea. I. Decapoda. Quart. fourn. Micr. Sci., Vol. 75, pp. 181-249.

- 195I. Muscle receptor organs in the abdomen of Homarus vulgaris and Palinurus vulgaris. Quart. Fourn. Micr. Sci., Vol. 92, pp. 163-99.

- I $952 a$. Notes on the nervous system in the Stomatopoda. I. The system of median connectives. Pubbl. Staz. Zool. Napoli, Vol. 23, pp. $201-14$.

- $1952 b$. Receptor elements in the thoracic muscles of Homarus vulgaris and Palinurus vulgaris. Quart. Fourn. Micr. Sci., Vol. 93, pp. 315-46.

- in press. Notes on the nervous system in the Stomatopoda. II. System of dorsal trunks. Pubbl. Staz. Zool. Napoli. 
Hanström, B., 1928. Vergleichende Anatomie des Nervensystems der wirbellosen Tiere. Schmid, W., I915. Die Muskulatur von Astacus fluviatilis (Potamobius astacus L.). Zeitschr. wiss. Zool., Bd. I13, pp. 165-251.

\section{EXPLANATION OF PLATES I-IV}

All photomicrographs were made from preparations stained with methylene blue, fixed in ammonium molybdate and mounted in xylol-dammar.

\section{Plate I}

Fig. I. Maia squinado. Pericardial organs of the left side (cf. Text-fig. I). Parts of the pericardium are still attached to the trunks.

Fig. 2. M. squinado. Posterior part of the pericardial organs. The ramifying branches end on the muscle fibres; the destination of some of them is uncertain.

Fig. 3. M. squinado. Part of the posterior bar showing the intermingling of nerve fibres. The small dots are elements of neuropiles.

Fig. 4. Cancer pagurus. Anterior portion of the pericardial organs of the right side. The trunks span the second opening of the branchio-cardiac veins. On the left upper corner is part of the first opening into which pass the anterior prolongations of the bars. Note the absence of neuropile sheaths in the lower parts of the trunks. These parts are embedded in the tissue of the pericardium. The situation of the bars is a little distorted artificially (cf. Text-fig. 2A).

\section{Plate II}

Fig. 5. Maia squinado. Part of the posterior bar. mot., fibres of the motor nerves passing through the pericardial organs without branching in them.

Fig. 6. M. squinado. Dorsal part of the anterior bar of the right side. n.mot., motor nerve; n.dors., fibres of the dorsal heart nerve; n.c., nerve cell.

Fig. 7. Cancer pagurus. Nerve fibre entering the anterior bar and ramifying in the trunks (cf. Text-fig. 2B).

Fig. 8. C. pagurus. Part of a trunk of the pericardial organs with fibres branching in it. Nearly all nerve elements seen in this and in the preceding figure belong to one neuron. They show well owing to the incomplete staining of the superficial layer of neuropiles (seen as small dots).

\section{Plate III}

Fig. 9. Eupagurus bernhardus. Part of the main trunk of the pericardial organs near its posterior end (cf. Text-fig. 3A).

Fig. Io. E. bernhardus. Part of the main trunk with a nerve fibre sending ramifications into different branches of the trunk.

Fig. II. Leander serratus. Pericardial organs of the right side. The position of the trunks is somewhat distorted by spreading and mounting the preparation (cf. Text-fig. 3B).

Fig. I2. L. serratus. Part of the pericardial organs of the left side, showing the changing of the appearance of the nerves coming from the central nervous system at the point where they pass into the trunks.

\section{Plate IV}

Fig. 13. Homarus vulgaris. Second and 3 rd trunks of the pericardial organs (cf. Text-fig. 4).

Fig. I4. H. vulgaris. Part of the 3 rd trunk of the pericardial organ with the strands securing its suspension (on the right).

Fig. 15. H. vulgaris. Parts of the trunk of the pericardial organs showing the characteristic beaded appearance of finer fibres.

Fig. I6. H. vulgaris. Fibres arising from the trunk of the pericardial organs (lower left corner) and spreading in one plane. The dots seen in some places are elements of neuropiles stained indistinctly. 

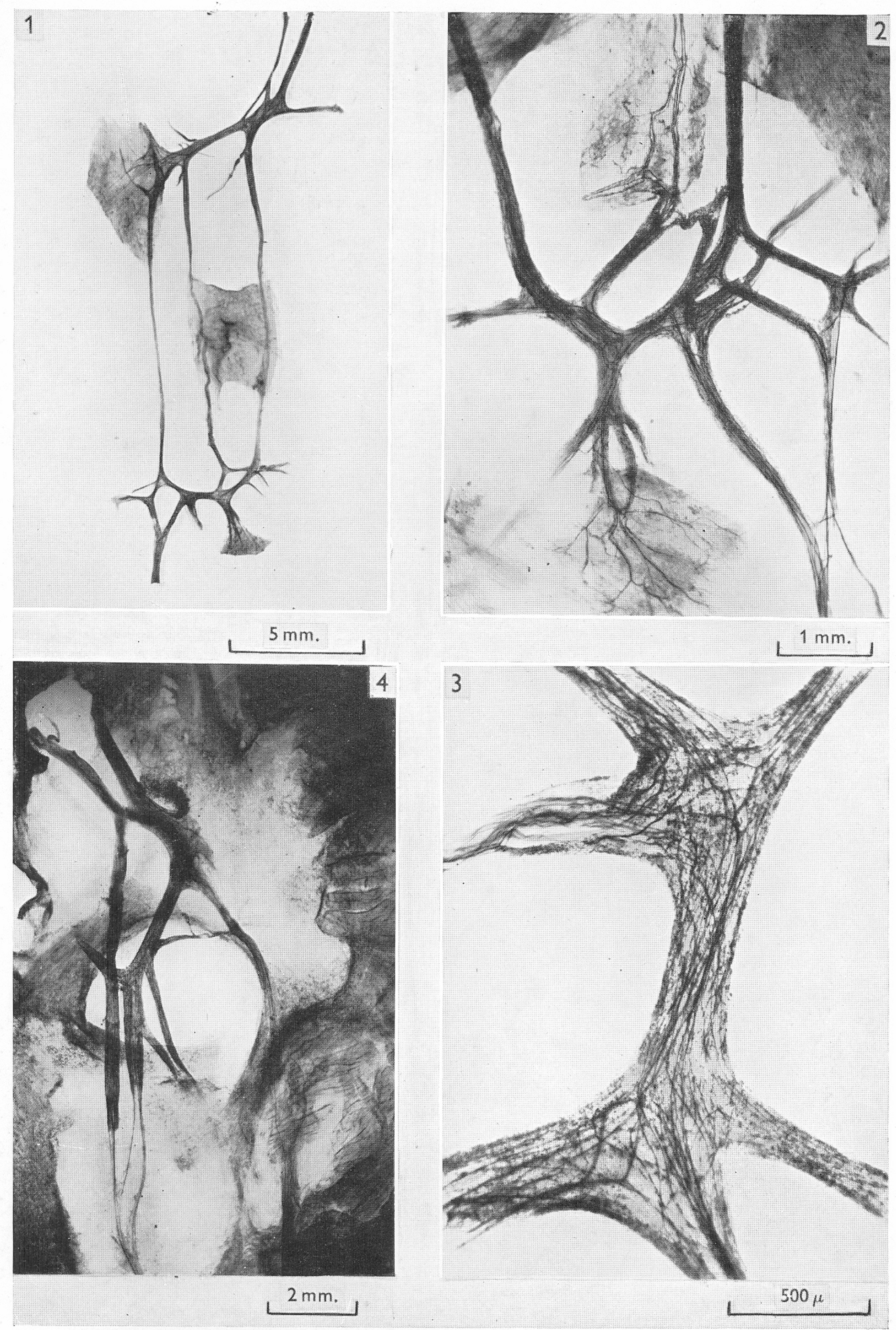

Figs. I-4 


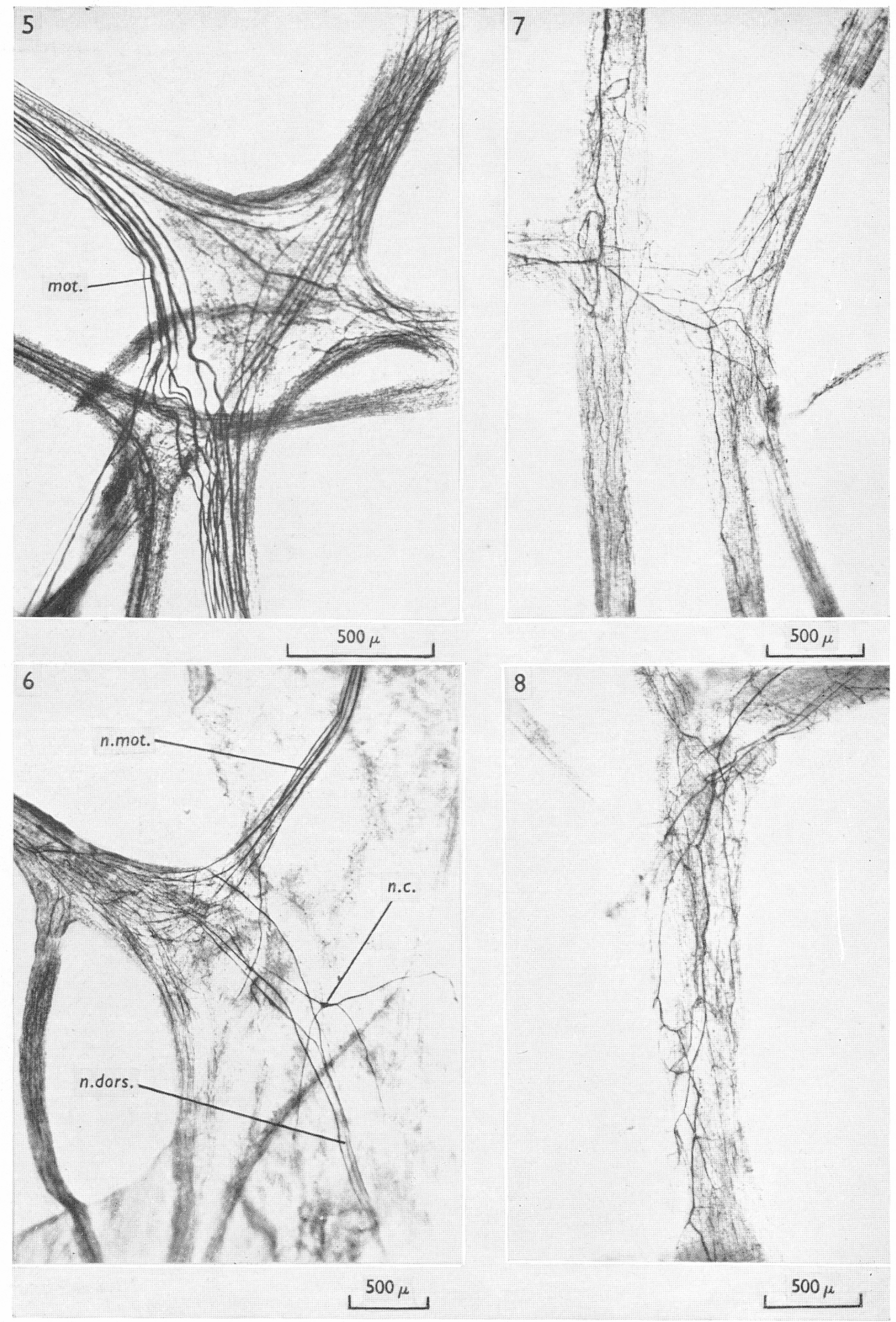

Figs. 5-8. 

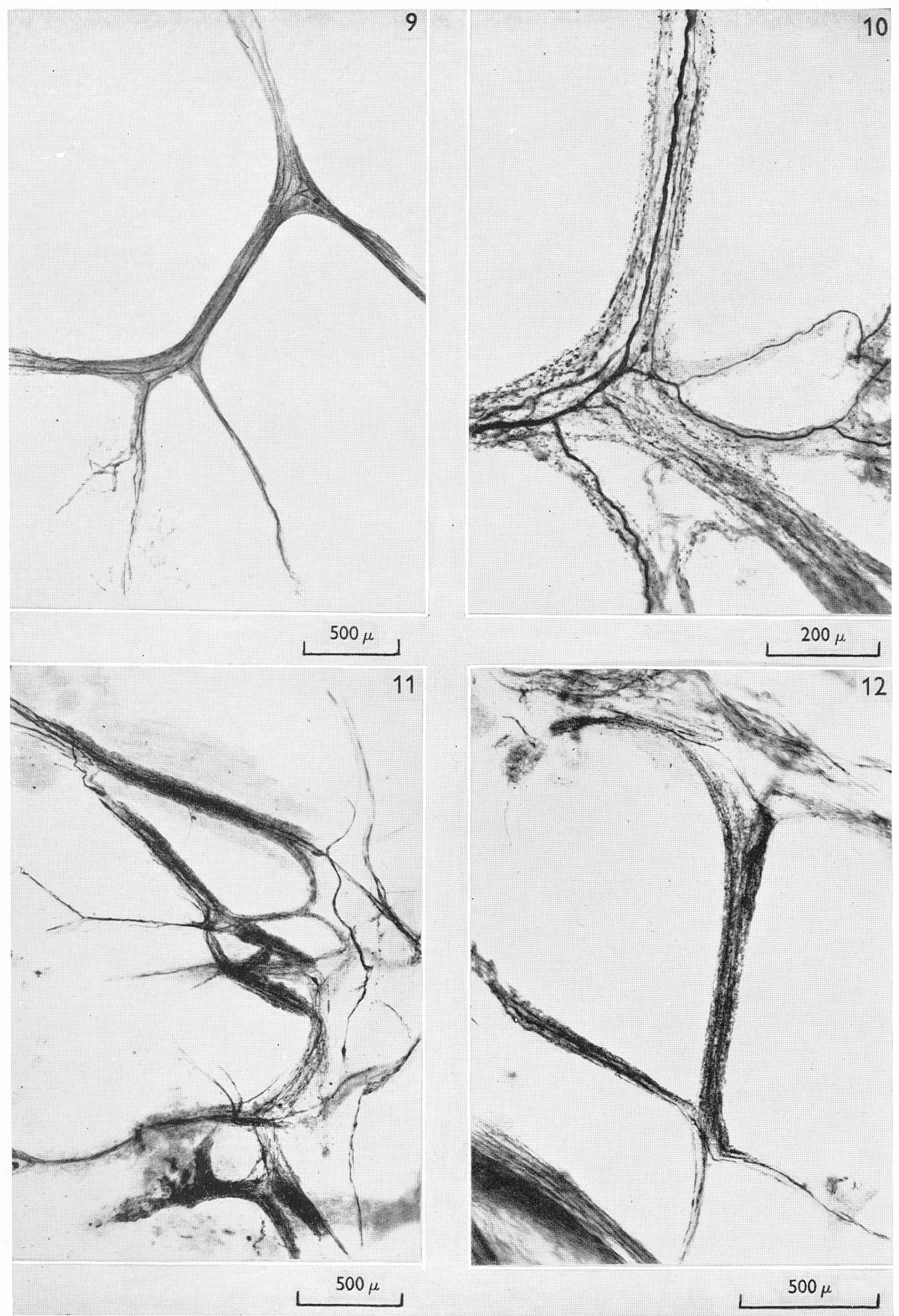

Figs. 9-I2. 


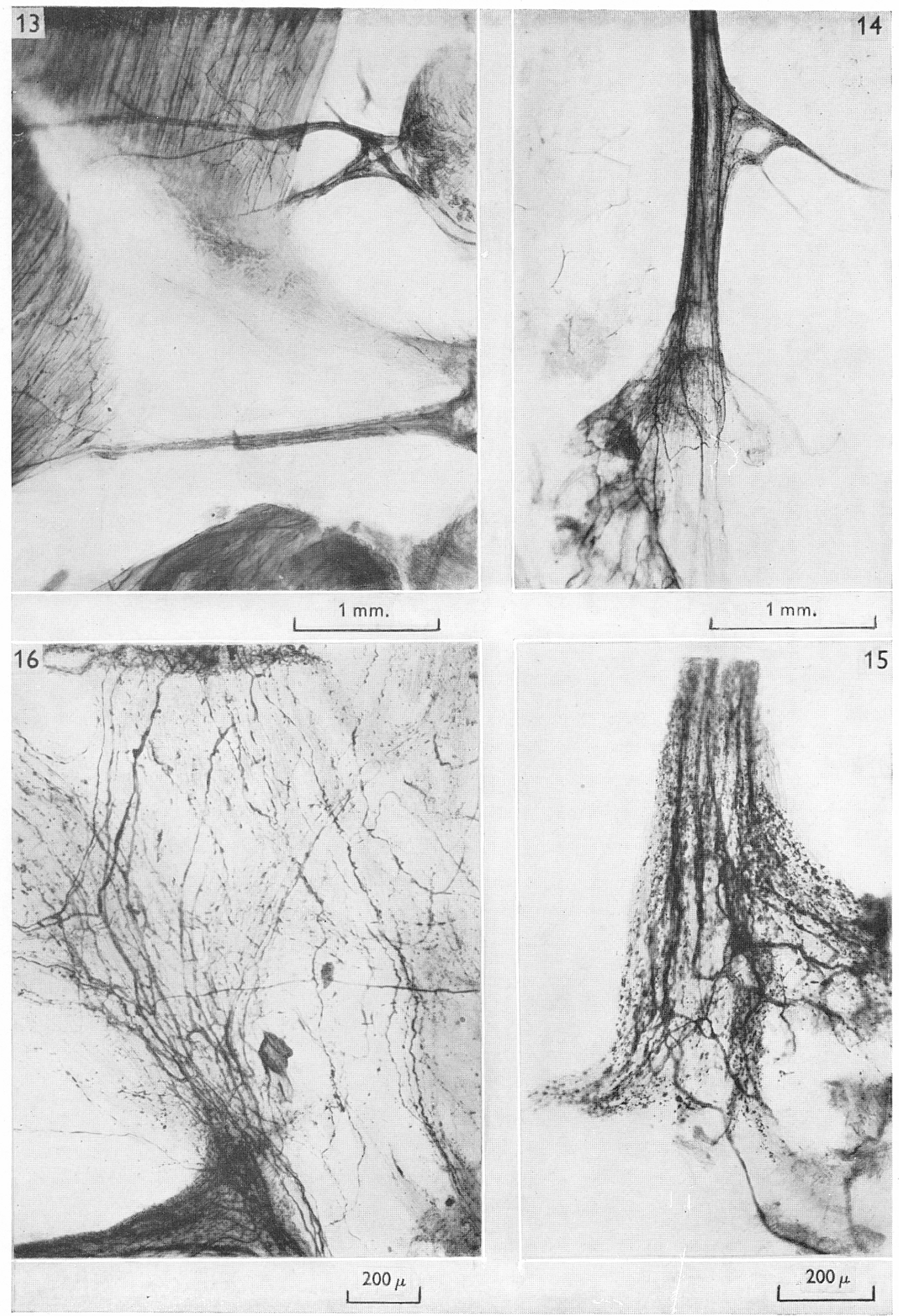

Figs. I3-I6. 